\title{
ASSESSMENT OF BONY UNION AFTER INTERBODY FUSION OF THE LUMBAR SPINE USING A BIPLANAR RADIOGRAPHIC TECHNIQUE
}

\author{
MARK PEARCY, SIMON BURROUGH
}

From the Oxford Orthopaedic Engineering Centre, and Horton General Hospital, Banbury

\begin{abstract}
Assessment of bony union after anterior fusion of the lumbar spine has previously relied on the skilled interpretation of plain radiographs. A biplanar radiographic technique was used to measure small movements between vertebrae and to give a quantitative measure of bony union in 11 patients who had undergone interbody fusion with autogenous bone chips at one level in the lumbar spine.

The investigation gave three types of results: bony union, where the fused level showed marked restriction of movement relative to the rest of the lumbar spine; paradoxical movement, where the fused joint showed marked reverse movement (when the patient flexed, the fused level of the lumbar spine extended) which was thought to be due to an anterior bony bar which caused an altered pattern of movement; and non-union, where the level of fusion showed no restriction of movement. The intervertebral joint above the level of fusion was shown to move more than the other joints in the lumbar spine.
\end{abstract}

The study showed that bony union is possible with the use of autogenous cancellous bone chips, and that a biplanar radiographic technique can determine the extent of union.

Chronic back pain may be diagnosed as being of mechanical origin if there is evidence of segmental instability at a discrete level. There may be a single narrowed disc space with or without displacement or slip of one vertebra relative to its neighbour. Pain resulting from such mechanical "instability" is generally aggravated by movement, and spinal fusion may be advised to reduce or prevent movement between two vertebrae and to prevent progressive slip.

Study of the mechanics of the lumbar spine indicates that interbody fusion as opposed to posterior element fusion is necessary to reduce movement between two vertebral bodies (Rolander 1966; Pearcy 1979). Assessment of the success of a fusion operation on the lumbar spine may be based on two criteria, relief of pain and union of the grafted area.

Reports of review after fusion operations indicate that solid fusion does not necessarily bring relief of pain, while pain relief does not imply solid fusion (Nelson 1965; Taylor 1970; Stauffer and Coventry 1971, 1972a, 1972b). Present radiographic techniques for determining bony union rely on plain radiographs in flexion and extension and are generally agreed to be unreliable (Finneson 1973; Pearcy 1979). Accurate measurement of movement of the lumbar spine is now possible with a biplanar radiographic technique (Stokes et al. 1981).

The present paper considers both the use of iliac crest bone chips instead of block grafts for anterior interbody fusion, and the use of biplanar radiography to assess the result of grafting in producing a stable fusion.

\section{MATERIAL}

Patients with chronic intractable backache of a type suggestive of segmental instability were selected. The most clear-cut radiological findings were in spondylolisthesis. The least obvious findings were in those patients with interbody joint disease of sufficient magnitude at one level to correlate with symptoms. The usual appearance in this group was of disproportionate loss of space at a single intervertebral disc, thickening of the subchondral plate and sufficient deformity to suggest increased movement. This may be compared with the deformity that occurs in the medial joint space as a result of varus instability of the knee. Eleven patients, in whom either the L5-S1 or the L4-5 level had been grafted, were investigated after operation. Details of the patients are given in Table $\mathbf{I}$.

\section{METHODS}

Surgical technique. Freebody, Bendall and Taylor (1971) advocated the use of a carefully shaped block of iliac crest bone to provide early stability after operation, and this graft has been referred to as a load-bearing member. The technique reported uses iliac crest bone chips rather than a single bone block.

At the beginning of the operation a block of bone was taken from

M. J. Pearcy, PhD, Research Assistant, Oxford Orthopaedic Engineering Centre, Nuffield Orthopaedic Centre, Headington, Oxford. S. J. Burrough, FRCS. Consultant Orthopaedic Surgeon, Horton General Hospital, Banbury.

Requests for reprints should be sent to Dr M. J. Pearcy.

(1) 1982 British Editorial Society of Bone and Joint Surgery 0301-620X/82/2031-0228 $\$ 2.00$ 
the ilium and cut into chips, each of which included part of one cortex. A transperitoneal approach for L5-S1 or a retroperitoneal approach for L4-5 was made through a separate incision, and dissection completed to expose the anterior longitudinal ligament overlying the selected disc. This ligament was then incised in a cruciate manner and the disc excised as far back as possible. The identification of the posterior longitudinal ligament proved difficult in the presence of a significant slip at L5-S1. Because of the position of the adjacent vertebral bodies, the posterior longitudinal ligament is angled away from the rongeur. A cavity can be cut into the middle of the body of L5. but one can only be cut into the anterior two-thirds of the top of the sacrum (Fig. 1). The posterior border of the body of L5 can be felt with

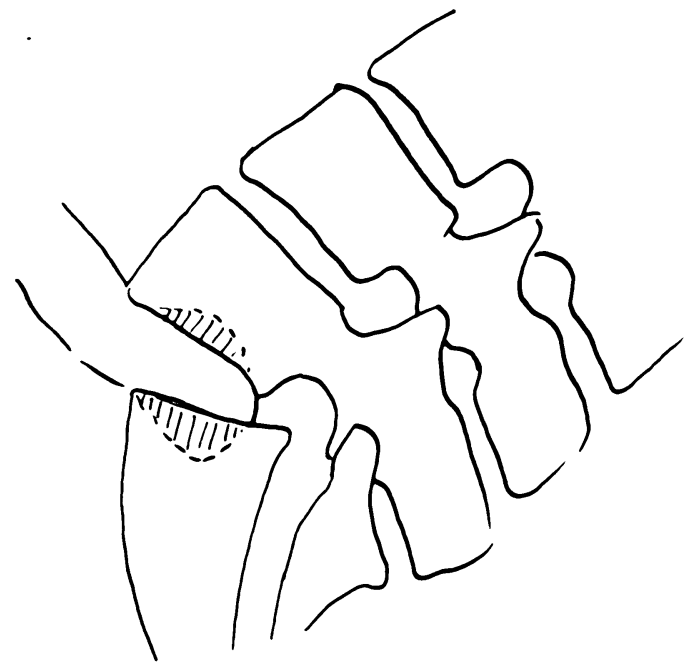

Fig. 1

Diagram of the lumbosacral junction showing the concavities cut in the vertebrae and the inaccessibility of the posterior border of the sacrum.

a finger, but the posterior border of the sacrum is out of reach. Cavities were made using small osteotomes to breach the cortical bone and then developed with a long Volkmann's spoon. The resulting cavity was packed with chip grafts impacted by using the closed end of a Northfield's rongeur. The cut anterior longitudinal ligament was then closed with chromic cutgut and the wound closed.

Patients were nursed on a Stryker frame or "log rolled" in bed for three weeks and then put into a plaster jacket for nine weeks. A well-fitting corset was then used for three months.

Biplanar radiography. At least eight months after operation 11 patients were studied using a biplanar radiographic technique developed at the Oxford Orthopaedic Engineering Centre (Stokes 1979). The technique uses a calibrated jig containing two $x$-ray tubes set at right angles to each other. This enables an anteroposterior and a lateral radiograph to be taken in rapid sequence while the patient is in

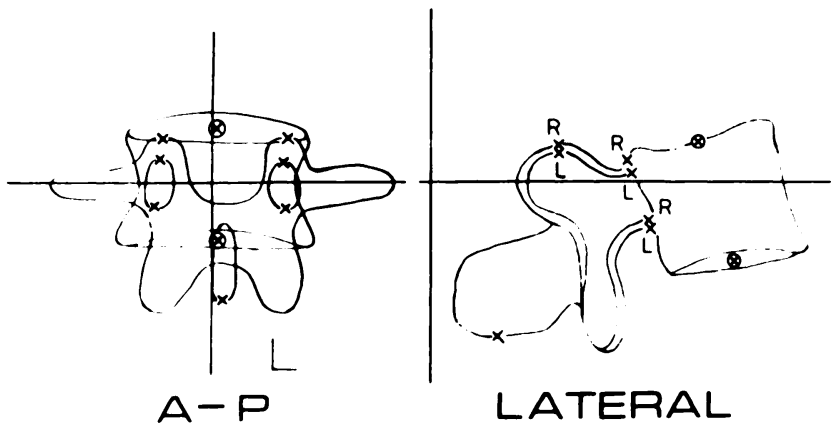

Fig. 2

Diagram showing the nine anatomical landmarks on the vertebrae used to obtain co-ordinates.

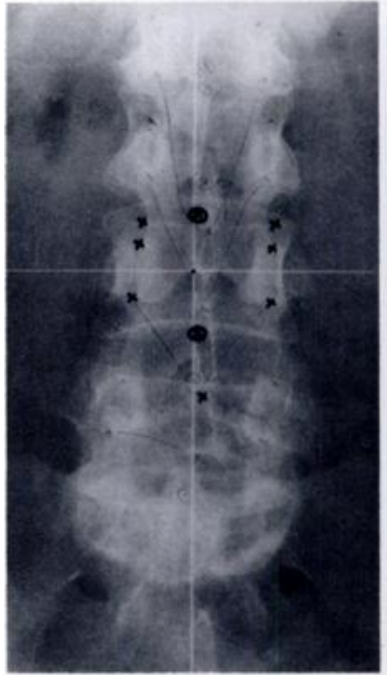

Fig. 3

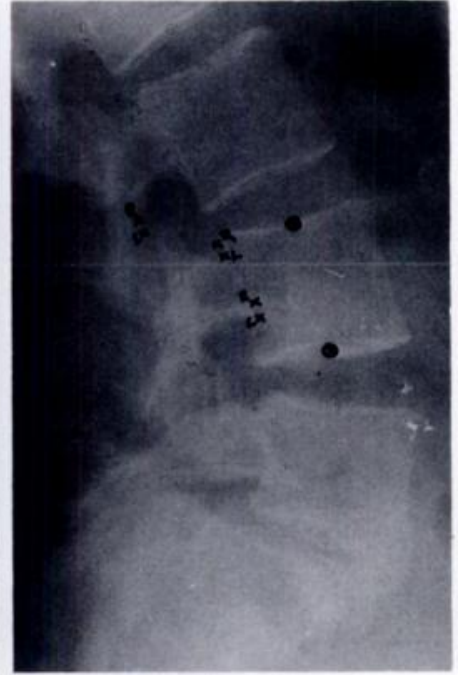

Fig. 4
Anteroposterior and lateral radiographs showing the nine landmarks on the vertebrae.

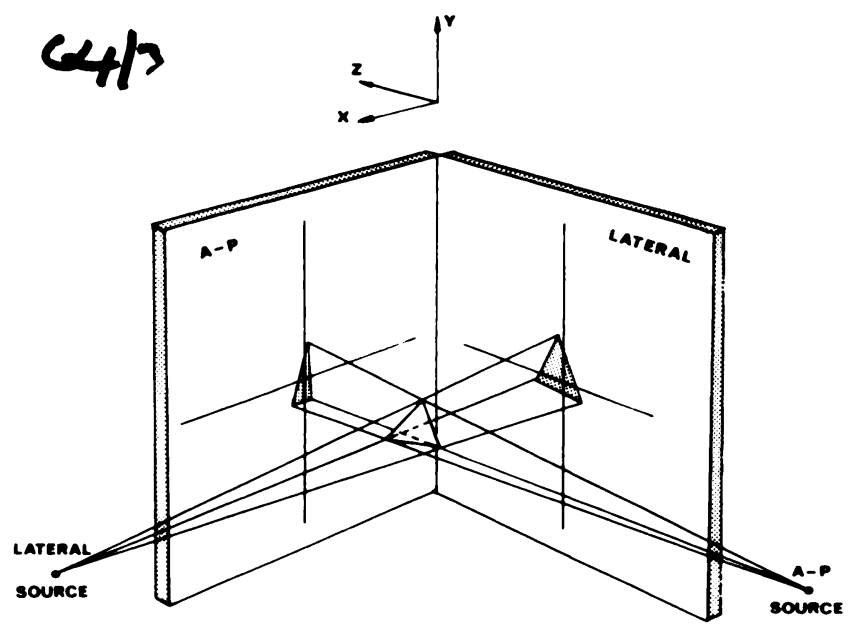

Fig. 5

Geometric constuction showing the projection of points on a body onto two orthogonal planes.

one position. In the investigation of movements of the lumbar spine. biplanar pairs of radiographs were taken with the patient standing in each of three positions, neutral, in forward flexion and in extension.

Nine anatomical landmarks were located and marked on each vertebra in each biplanar view (Figs 2, 3 and 4). The co-ordinates of these points were then obtained using a digitising tablet and a PDP 11-34 computer. The computer then calculated the three-dimensional co-ordinates of these points. using the geometric construction shown in Figure 5. Comparison of the co-ordinates obtained in the three different positions of the patient enabled the calculation of the intersegmental rotation occuring between these positions to be performed with an accuracy of between two and three degrees (Stokes 1979).

\section{RESULTS}

The results are given in Table $I$. The first column indicates the results of biplanar radiography at the grafted level. Marked restriction of movement was taken to indicate fusion, and unrestricted movement indicated non-union; the patients showing paradoxical movement also showed some general restriction of 
Table I. Details of patients undergoing bone grafting at the L4-L5 or L5-S1 levels and summary of results

\begin{tabular}{|c|c|c|c|c|c|c|c|c|}
\hline \multirow[b]{2}{*}{ Case } & \multirow[b]{2}{*}{ Sex } & \multirow{2}{*}{$\begin{array}{c}\text { Age at } \\
\text { operation } \\
\text { (years) }\end{array}$} & \multirow[b]{2}{*}{$\begin{array}{l}\text { Level of } \\
\text { fusion }\end{array}$} & \multirow{2}{*}{\multicolumn{2}{|c|}{$\begin{array}{c}\text { Time since } \\
\text { operation } \\
(y+m)\end{array}$}} & \multicolumn{3}{|c|}{ Results } \\
\hline & & & & & & Fusion level & $\begin{array}{l}\text { Lumbar } \\
\text { mobility }\end{array}$ & $\begin{array}{c}\text { Clinical } \\
\text { assessment }\end{array}$ \\
\hline 1 & $F$ & 51 & L5-S1 & 5 & 2 & Union & Mobile & Better \\
\hline 2 & $\mathrm{~F}$ & 43 & L4-L5 & 4 & 2 & Union & Mobile & Cured \\
\hline 3 & $\mathrm{~F}$ & 39 & L5-S1 & 2 & 9 & Union & Mobile & Better \\
\hline 4 & $\mathbf{M}$ & 28 & L5-S1 & 4 & 7 & Union & Mobile & Better \\
\hline 5 & $\mathrm{~F}$ & 58 & L5-S1 & 1 & 4 & Union & Restricted & Better \\
\hline 6 & $F$ & 71 & L4-L5 & 1 & 3 & Paradoxical & Mobile & Better \\
\hline 7 & $F$ & 37 & L5-S1 & 5 & 5 & Paradoxical & Mobile & Cured \\
\hline 8 & $\mathbf{M}$ & 43 & L5-S1 & 5 & 4 & Non-union & Restricted & Same \\
\hline 9 & $\mathbf{M}$ & 50 & L5-S1 & 0 & 10 & Non-union & Restricted & Worse \\
\hline 10 & $\mathrm{~F}$ & 48 & L5-S1 & 5 & 6 & Non-union & Restricted & Cured \\
\hline 11 & $\mathrm{~F}$ & 27 & L4-L5 & 5 & 7 & Non-union & Mobile & Cured \\
\hline
\end{tabular}

Table II. To show the percentage of total movement taking place at each of four levels in the lumbar spine

\begin{tabular}{|l|l|c|c|c|}
\hline \multicolumn{1}{|c|}{ Group } & \multicolumn{1}{|c|}{ Level } & $\begin{array}{c}\text { Mean } \\
\text { (per cent })\end{array}$ & SD & Number \\
\hline 8 patients with back & L2-3 & 28.7 & 6.8 & 8 \\
pain before operation & L3-4 & 25.3 & 9.8 & 8 \\
& L4-5 & 23.5 & 6.8 & 8 \\
& L5-S1 & 22.5 & 13.0 & 8 \\
\hline 11 patients after & Operation & 18.1 & 13.9 & 11 \\
operation at one level & 1 above & 35.3 & 15.3 & 11 \\
& 2 above & 22.4 & 9.9 & 11 \\
& 3 above & 25.3 & 12.5 & 8 \\
\hline 5 patients with sound & Bony union & 6.5 & 5.1 & 5 \\
fusion at one level & 1 above & 44.6 & 14.2 & 5 \\
& 2 above & 28.2 & 8.9 & 5 \\
& 3 above & 24.0 & 13.4 & 4 \\
\hline
\end{tabular}

movement and the radiological evidence indicated that the graft might have fused anteriorly. The second column gives a radiographic assessment of the mobility of the lumbar spine as a whole, and the third column gives a clinical assessment of the results at the time of radiography.

The biplanar radiographic results are presented in detail in Figure 6, which shows intervertebral movements in the lumbar spine for each of the 11 patients. The upper histogram gives the movement at each segment on voluntary flexion from the neutral position while the lower blocks give the movement on voluntary extension. The figures for the first five patients show marked restriction of movement at the fused level in comparison with other levels of the lumbar spine in both flexion and extension and are considered to show solid bony union. The last four patients show a grafted level which is mobile when compared with the rest of the lumbar spine and are considered to have non-union. The remaining two patients show marked "paradoxical" movements. A paradoxical movement is recorded when one or more intervertebral segments move in the opposite direction to the voluntary movement attempted by the patient. This is seen in Case 7 (BM), where the grafted level moved into extension as the patient flexed.

Table II shows the range of movement at each level of the lumbar spine under investigation. Eight patients with backache and no history of operation showed no significant differences between movements at any level (Student's $t$-test). The patients who had undergone operation for anterior fusion showed a significant increase in movement $(P<0.05)$ at the level above the fusion compared to the average at other levels. This difference is highlighted when only those patients showing definite bony union after fusion are considered. In this group the level above the fusion showed almost twice as much movement as the average of other levels $(P<0.025)$. 


\section{DISCUSSION}

There was evidence from conventional radiographs of bony union between the two grafted vertebrae in all but one patient (Case 11). This evidence consisted of the appearance of trabeculae crossing the fusion mass, and of remodelling of the anterior edges of the end-plates. Biplanar radiographic measurements showed some intersegmental movement in five patients with conventional evidence of fusion. This situation could be explained if only a thin bar of bone had been incorporated. This bar would be flexible and would alter the centre of rotation of the intervertebral joint. The small paradoxical movement seen in several of the patients may be normal, but the exaggerated nature of these in two patients (Cases 6 and 7) is evidence that the

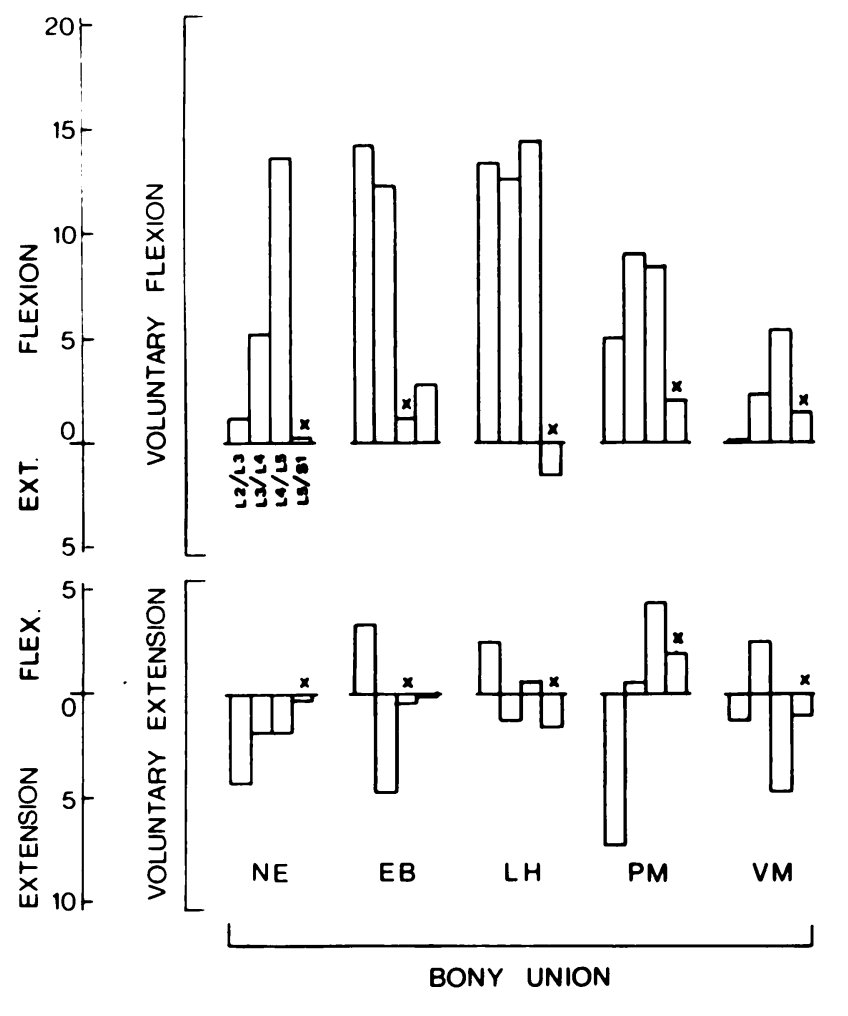

The comparison of movement at different levels gives clear evidence that there is increased movement at the level above a fusion. This tends to compensate for the loss of movement at the fusion, but it is possible that this increased movement may lead to earlier mechanical deterioration.

The use of bone chips as a graft instead of a load-bearing block has been shown to lead to successful incorporation. However, the patients in this series already had a narrowed disc space, and although it may be possible to maintain a space that has not completely collapsed by packing it with bone graft, there is likely to be some subsequent disc space narrowing. The function of a block graft is to provide mechanical stability while healing takes place. Any graft is incorporated by so called "creeping substitution" of the bone, and thus a
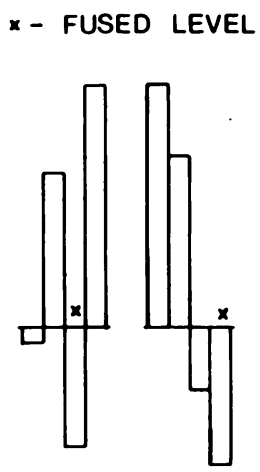
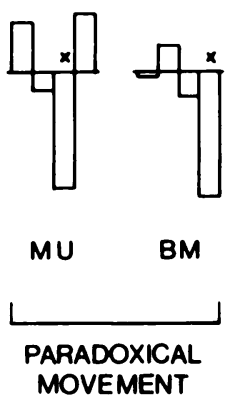
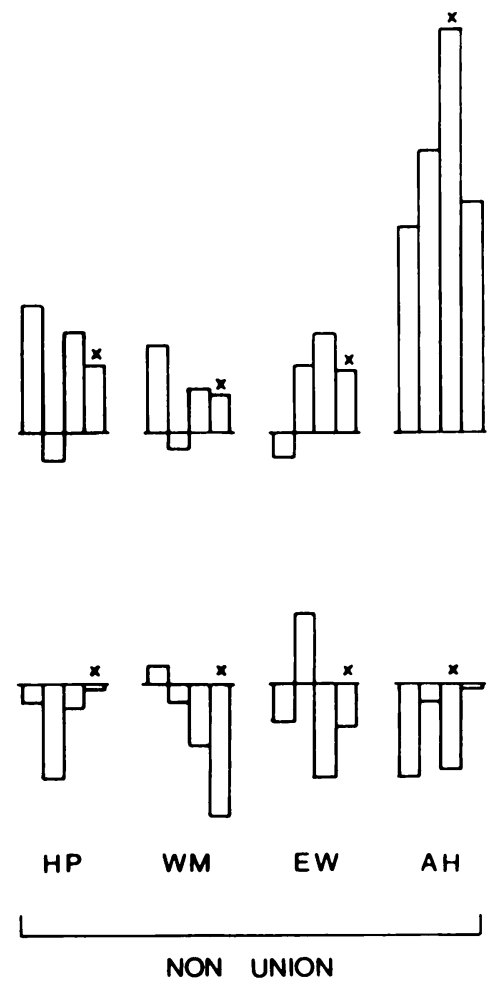

Fig. 6

Histogram to show the movement in degrees of the intervertebral joints of 11 patients. Each set of blocks shows from left to right L2-3, L3-4, L4-5 and L5-S1.

normal mechanics of the spine have been altered. A theoretical model is being developed to predict the movement to be expected with the bony bar at different locations in association with disruption of the posterior elements of the intervertebral joint.

A small bony bar may allow rotational movement about itself as a fulcrum but it will severely limit shearing movement. In some lesions of the spine it may be that shearing movement is the cause of pain, and the success of the operation may be related to the restriction of shear. The accurate measurement of anteroposterior shearing movement must await further technical development of the biplanar radiographic technique. large block takes longer to incorporate than bone chips, thereby increasing the risk of separation between the graft and the vertebrae. Provided that the fusion site can be splinted adequately either by the conservative methods described or by mechanical fixation, union will occur faster with bone chips, and provide better surgical results.

This conflict between the mechanical and biological properties of the graft could be resolved by use of a block graft surrounded by bone chips. However, it is suggested that bone chips alone are sufficient with a regime after operation which splints the spine during the initial healing period. A major limitation of this study is that 
movement of the fused level of each patient was compared only after operation with that of the rest of the lumbar spine. This research is to be continued by examining patients before, as well as after operation to study the effect of operation at one level on the pattern of movement of the whole lumbar spine. This study has demonstrated that iliac crest bone chips can promote bony union in interbody fusion.

The biplanar radiographic technique has been shown to provide measurement of intervertebral movement sensitive enough to demonstrate the degree of limitation at the grafted level after a fusion procedure.

The radiographic equipment for this work was provided by G.E.C. Medical Equipment, Wembley, England.

\section{REFERENCES}

Finneson BE. Low back pain. Philadelphia, Toronto: J. B. Lippincott \& Co., 1973.

Freebody D, Bendall R, Taylor RD. Anterior transperitoneal lumbar fusion. J Bone Joint Surg [Br] 1971;53-B:617-27.

Nelson MA. Anterior fusion of the lumbar spine: review of 24 patients. Proc $R$ Soc Med 1965;58:331-3.

Pearcy MJ. A biomechanical analysis of interbody fusion of the lumbar spine. PhD thesis, University of Strathclyde, 1979.

Rolander SD. Motion of the lumbar spine with special reference to the stabilizing effect of posterior fusion. Acta Orthop Scand 1966; suppl 90. Stauffer RN, Coventry MB. Anterior interbody lumbar spine fusions: analysis of Mayo Clinic series.J Bone Joint Surg [Am] 1971;53-A:1655-6.

Stauffer RN, Coventry MB. Anterior interbody lumbar spine fusion: analysis of Mayo Clinic series. J Bone Joint Surg [Am] 1972a;54-A:756-68.

Stauffer RN, Coventry MB. Posterolateral lumbar-spine fusion: analysis of Mayo Clinic series.J Bone Joint Surg [Am] 1972b;54-A:1 195-1204.

Stokes IAF. Techniques of analysis of biplanar films. In: the 1979 annual report of the Oxford Orthopaedic Engineering Centre, Nuffield Orthopaedic Centre, Headington, Oxford, England, 1979.

Stokes IAF, Wilder DG, Frymoyer JW, Pope MH. Assessment of patients with low back pain by biplanar radiographic measurement of intervertebral motion. Volvo award winning paper to be published in Spine 1981;6:233-40.

Taylor TKF. Anterior interbody fusion in the management of disorders of the lumbar spine. J Bone Joint Surg [Br] 1970;52-B:784. 